\title{
Musculoskeletal disorders and the physical activity of territorial army soldiers during the COVID-19 pandemic
}

\author{
Małgorzata Grabara and Ewa Sadowska-Krępa*
}

\begin{abstract}
Background: The aim of this study was to assess the occurrence of self-reported musculoskeletal disorders (MSD) among Polish territorial army soldiers during the COVID-19 pandemic and to investigate whether there was a relationship between occupational physical activity (OPA), leisure time physical activity (LTPA), and MSD.

Methods: The study used a cross-sectional design with a sample of 373 territorial army soldiers ages $18-55$ who had not previously suffered from COVID-19 and were not convalescents. The symptoms prevalence data was collected using the standardized Nordic Musculoskeletal Questionnaire. OPA and LTPA data was collected using the Seven-Day Physical Activity Recall (SDPAR).

Results: The OPA, LTPA, and total physical activity (PA) among the studied soldiers was very diverse and the mean level of PA was relatively high. A total of 56 and $40 \%$ of territorial army soldiers had experienced pain or other discomfort in one or more of nine body regions during the past 12 months and during the past 7 days, respectively. The most common MSD among Polish territorial army soldiers were low back pain, followed by pain in the neck and knees.

Conclusions: The study revealed that the OPA of the studied soldiers, especially vigorous-intensity and high vigorous-intensity OPA, was associated with a higher prevalence of MSD in several regions of the body, i.e. the lower back, elbows, wrists or hands, hips or thighs, and ankles or feet. Along with the increase in energy expenditure on total PA, a greater percentage of respondents experienced low back pain. Vigorous and high vigorous-intensity PA may contribute to the occurrence of MSD.
\end{abstract}

Keywords: Musculoskeletal symptoms, Occupational physical activity, Leisure time physical activity, seven-day physical activity recall, COVID-19

\section{Background}

Musculoskeletal disorders (MSD) defined as selfreported musculoskeletal symptoms are prevalent in working populations worldwide and cause major health issues [1, 2]. Disorders of the muscles, tendons, joints, and spinal discs may be caused by work and lead to a decrease in work effectiveness and quality of life $[3,4]$.

\footnotetext{
* Correspondence: e.sadowska-krepa@awf.katowice.pl Institute of Sport Sciences, Jerzy Kukuczka Academy of Physical Education Katowice, Poland
}

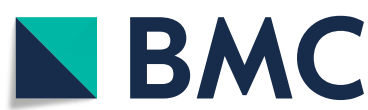

(c) The Author(s). 2021 Open Access This article is licensed under a Creative Commons Attribution 4.0 International License, which permits use, sharing, adaptation, distribution and reproduction in any medium or format, as long as you give appropriate credit to the original author(s) and the source, provide a link to the Creative Commons licence, and indicate if changes were made. The images or other third party material in this article are included in the article's Creative Commons licence, unless indicated otherwise in a credit line to the material. If material is not included in the article's Creative Commons licence and your intended use is not permitted by statutory regulation or exceeds the permitted use, you will need to obtain permission directly from the copyright holder. To view a copy of this licence, visit http://creativecommons.org/licenses/by/4.0/. The Creative Commons Public Domain Dedication waiver (http//creativecommons.org/publicdomain/zero/1.0/) applies to the data made available in this article, unless otherwise stated in a credit line to the data. may lead to a high risk of MSD. Previous studies also involving the military population have suggested that age, tall body height, low aerobic fitness and endurance, extremes in flexibility, prior injury, participation in recreational sports activity, a history of prior limited PA, and even older running shoes are risk factors for developing MSD [5-8].

The beneficial effects of PA are well documented, however this documentation is restricted to leisure time 
physical activity (LTPA). Emerging studies have shown that this effect differs depending on the domain of the PA [9], i.e. occupational physical activity (OPA), household PA, active transport, and LTPA. Several studies have demonstrated that OPA is not beneficial for health due to its too low intensity, too long duration, static and constrained postures, and insufficient recovery time [10, 11]. Moreover, the dose of PA is also important. Greater intensities and volumes of exercise may lead to greater the risk of injury and harm, specially musculoskeletal [12]. Based on WHO recommendations, a longer duration of moderateintensity PA leads to achieving the same health benefits as shorter durations of vigorous-intensity PA [13].

PA is described as a benefit for workers in the context of decreasing the risk of musculoskeletal disorders. Previous studies have indicated that PA can prevent and reduce the occurrence of MSD regardless of age [2, 1416]. However, a majority of them were limited to the assessment of LTPA. There is limited knowledge about PA as a factor in preventing MDS, and studies on the association between PA and MSD reveal inconsistent results $[17,18]$. Physical training may also be a source of musculoskeletal injuries.

The role of the territorial defense forces in Poland is crisis prevention. During the COVID-19 pandemic their role has been special, although the training of soldiers is different than during a non-pandemic period. Considering the commonly known negative effects of the pandemic on citizen [19], and health [20, 21], the main role of the territorial defense forces was to provide comprehensive service for the civilian population. From January 2020 to August 2021, Poland submitted to the WHO [22], 2,883,120 confirmed cases of COVID-19 with 75,261 deaths.

Service in the territorial armies is voluntary and the number of vocations depends on the capabilities and availability of the volunteers, who are professionally active and represent different levels of PA. However, all soldiers are obliged to maintain their physical fitness individually, with the army providing them the opportunity to use the gym and improve their swimming skills at a swimming facility up to $2 \mathrm{~h}$ a week. They are required to pass an annual fitness test. The necessity of undertaking PA among soldiers could have an influence on MSD.

The aim of this study was to assess the occurrence of self-reported musculoskeletal disorders among male and female territorial army soldiers during the COVID-19 pandemic, and to investigate whether there was a relationship between occupational physical activity, leisure time physical activity, and MSD.

\section{Methods}

\section{Study design}

A cross-sectional survey research of male and female Polish territorial army soldiers was performed. This study was approved by the Bioethics Committee of the Jerzy Kukuczka Academy of Physical Education in Katowice (certificate of approval No. KB/02/12) and conformed to the standards established by the Declaration of Helsinki. All participants were told about the type and purpose of the study and gave their informed consent prior to filling out the questionnaire.

\section{Participants}

The study recruited a sample of 373 territorial army soldiers ages $18-55$ years who had not previously suffered from COVID-19 and were not convalescents. However, it should be noted that participants were not tested, therefore if they were asymptomatic, they may have been infected without knowing.

The studied sample included all soldiers from one of the fifteen Territorial Defense Brigades in Poland who had completed the entire training cycle and were authorized to perform tasks related to their official duties. The inclusion criteria were: a) possession of a medical certificate of fitness to serve in the territorial army, b) successful completion of fitness examinations, c) at least 6 months of service in the territorial army, d) the consent to participate in the study. Participants who did not meet the inclusion criteria as well as those with missing data were excluded. The basic characteristics of the studied soldiers are presented in Table 1.

\section{Methods and procedures}

The study was conducted from October-November 2020 using a direct pen-and-paper interview method in the workplace of the studied participants.

The symptoms prevalence data was collected using the standardized Nordic Musculoskeletal Questionnaire (NMQ). NMQ contains a view of the human body imaged from the back and separated into the nine anatomical localizations which may be affected by musculoskeletal disorders. The NMQ quantifies musculoskeletal pain in the following body regions: neck, shoulders, upper back, elbows, low back, wrists/hands, hips/thighs, knees, and ankles/feet. The participants provided information related to their pain symptoms (discomfort, numbness, ache) during the last 12 months and during the last 7 days. In case of pain complaints during the last 7 days, an estimation of the pain intensity was given using a range of 1 to 10 (from a minimal to intense or unbearable pain) [23-25].

Body mass index was estimated on the basis of the participants' body height and weight.

Occupational and leisure time physical activity data was collected using the Seven-Day Physical Activity Recall (SDPAR) with the authors' own modification. The questionnaire serves for collecting data concerning the frequency, intensity, and duration of both occupational and leisure time PA as well as the time spent sleeping 
Table 1 Basic characteristic of the participants, declared time spent sitting per day, and energy expenditure (EE) on total physical activity (PA) during the week [kcal]

\begin{tabular}{|c|c|c|}
\hline Variables & $\mathrm{N}$ & $\%$ \\
\hline \multicolumn{3}{|l|}{ Gender } \\
\hline Men & 305 & $82 \%$ \\
\hline Women & 68 & $18 \%$ \\
\hline \multicolumn{3}{|l|}{ Age [years] } \\
\hline$<25$ & 85 & $23 \%$ \\
\hline $25-40$ & 212 & $57 \%$ \\
\hline$>40$ & 76 & $20 \%$ \\
\hline \multicolumn{3}{|l|}{ BMI } \\
\hline Underweight & 8 & $2 \%$ \\
\hline Healthy weight (norm) & 169 & $45 \%$ \\
\hline Overweight & 159 & $43 \%$ \\
\hline Obese & 37 & $10 \%$ \\
\hline \multicolumn{3}{|l|}{ Time spent sitting per day } \\
\hline$<2 h$ & 47 & $13 \%$ \\
\hline $2-4 h$ & 73 & $19 \%$ \\
\hline $4-6 h$ & 129 & $35 \%$ \\
\hline $6-8 \mathrm{~h}$ & 68 & $18 \%$ \\
\hline above $8 \mathrm{~h}$ & 56 & $15 \%$ \\
\hline \multicolumn{3}{|l|}{ EE on total PA } \\
\hline$<2000 \mathrm{kcal}$ & 87 & $23 \%$ \\
\hline 2000-3999 kcal & 66 & $18 \%$ \\
\hline $4000-6000 \mathrm{kcal}$ & 70 & $19 \%$ \\
\hline$>6000 \mathrm{kcal}$ & 150 & $40 \%$ \\
\hline
\end{tabular}

seven days prior to examination. Domestic PA and active transport (commuting PA) were included in leisure time PA, whereas active transport to work was included in occupational PA due to the sparse reporting of these activities by the studied soldiers (by four participants or less).

Participants declared their occupational physical activity (OPA) and leisure time physical activity (LTPA) separately (in minutes) for each day of the week, describing its intensity as moderate, vigorous, or highly vigorous, as well as the number of hours spent sleeping. They also declared the mean time spent sitting per day. The declared PA was estimated according to the SDPAR procedure: moderate-intensity PA - 4 METs, vigorousintensity PA - 6 METs, high-vigorous-intensity PA - 10 METs [26, 27]. Taking all the data into consideration, weekly and daily energy expenditures on PA were calculated [kcal, METmin].

\section{Statistical analysis}

Results are expressed as the means, standard deviations, medians, minimal and maximal values, and confidence interval (95\%) of standard deviations or are described using frequencies (percentage). The normality of distribution was verified with the Shapiro-Wilk test. To compare the number of soldiers within each category of energy expenditure (EE) on total PA, classified as $<2000$ kcal, 2000-3999 kcal, 4000-6000 kcal, and $>6000 \mathrm{kcal}$, and time spent sitting classified as $<2 \mathrm{~h}, 2-4 \mathrm{~h}, 4-6 \mathrm{~h}$, 6-8 h, above $8 \mathrm{~h}$, and BMI status classified as underweight $(<18.5)$, healthy weight (18.5-24.9), overweight (25.0-29.9), and obese $(\geq 30.0)$ with the number of workers with MSD (separately for each body region), Pearson's chi-squared test was used. To determine the relationship between PA and the prevalence of MSD, Spearman's rank correlation coefficient and multiple regression were applied. To compare PA (total as well as domain and intensity specific) between the soldiers who reported MSD classified as a lack of MSD, 1 or 2 MSD, or 3 or more MSD, the Kruskal-Wallis one-way ANOVA by ranks or one-way ANOVA was used. The level of significance was set at $p \leq .05$. Statistical analysis was undertaken using Statistica ver. 13, TIBCO Software Inc.

\section{Results}

The basic characteristic of participants regarding their sex, age, BMI, time sent sitting per day, and EE on total PA is shown in Table 1.

The occurrence of MSD during the last 12 months and the last 7 days is presented in Table 2. The 12-month prevalence of low back pain was $36 \%$, knee pain $22.5 \%$, and neck pain $21 \%$. The last 7-day prevalence of MSD in certain body regions was lower than the last 12 months. The highest average pain intensity was reported for the low back and knees (Table 2).

The occupational, leisure time, and total PA among studied soldiers was very diverse and the mean level of PA was relatively high (Table 3 ). As many as $40 \%$ of participants spent more than $6000 \mathrm{kcal}$ per week on their total PA, and only $15 \%$ of soldiers declared more than 8 h spent sitting per day (Table 1).

Based on energy expenditures on total PA during the week (as shown in Table 1), the analysis showed statistically significant differences in the prevalence of low back pain (Pearson $X^{2}=8.13, p=.043$ ). Other differences were not observed.

Based on declared time spent sitting per day and BMI status (as shown in Table 1), the analysis did not reveal any significant differences in the prevalence of MSD.

The association between PA and the occurrence of MSD during the last 7 days and during the last 12 months is presented in Figs. 1 and 2, respectively. The analysis showed a difference in high vigorous-intensity OPA $(p=.019)$ between soldiers who did not report any MSD during the last 7 days, those who reported 1-2 MSD, and those who reported 3 or more MSD during 
Table 2 The occurrence of musculoskeletal disorders (MSD) during the last 12 months and during the last 7 days, pain intensity of MSD during the last 7 days among soldiers $(n=373)$

\begin{tabular}{|c|c|c|c|c|}
\hline Area of body affected & $\begin{array}{l}\text { Occurrence of MSD during } \\
\text { last } 12 \text { months [n, \%] }\end{array}$ & $\begin{array}{l}\text { Occurrence of MSD } \\
\text { during last } 7 \text { days [n, \%] }\end{array}$ & $\begin{array}{l}\text { Pain intensity (1-10) of MSD } \\
\text { during last } 7 \text { days (min-max) }\end{array}$ & $\begin{array}{l}\text { Pain intensity }(1-10) \text { of MSD } \\
\text { during last } 7 \text { days (mean } \pm \text { sd) }\end{array}$ \\
\hline Neck & $78(21 \%)$ & $43(12 \%)$ & $1-9$ & $4.07 \pm 2.21$ \\
\hline Shoulders & $49(13 \%)$ & $31(8 \%)$ & $1-8$ & $4.23 \pm 1.90$ \\
\hline Upper back & $52(14 \%)$ & $36(10 \%)$ & $2-10$ & $4.56 \pm 2.28$ \\
\hline Elbows & $18(5 \%)$ & $10(3 \%)$ & $2-6$ & $4.30 \pm 1.10$ \\
\hline Wrists/hands & $39(20 \%)$ & $20(5 \%)$ & $1-8$ & $3.85 \pm 1.90$ \\
\hline Lower back & $134(36 \%)$ & $72(19 \%)$ & $1-10$ & $4.79 \pm 1.94$ \\
\hline Hips/thighs & $33(9 \%)$ & $24(6 \%)$ & $1-8$ & $4.25 \pm 2.03$ \\
\hline Knees & $84(23 \%)$ & $44(12 \%)$ & $1-10$ & $4.73 \pm 2.49$ \\
\hline Ankles/feet & $46(12 \%)$ & $33(9 \%)$ & $1-10$ & $2.47 \pm 2.21$ \\
\hline
\end{tabular}

the last 7 days. Differences in moderate-intensity OPA $(p=.006)$, total OPA $(p=.008)$, moderate-intensity LTPA $(p=.028)$, total LTPA $(p=.021)$, total PA [MET$\min ](p=.023)$, and total PA [kcal] $(p=.003)$ were found between soldiers who reported no MSD, those who reported 1-2 MSD, and those who reported 3 and more MSD during the last 12 months.

The following relationships between the prevalence of MSD during the last 12 months and PA were observed: the occurrence of elbow pain was correlated with vigorous-intensity OPA $(\mathrm{r}=0.10, p=.044)$, the occurrence of wrist or hand pain was correlated with high vigorous-intensity LTPA $(\mathrm{r}=0.11, p=.033)$, the occurrence of low back pain was correlated with moderateintensity OPA $(\mathrm{r}=0.17, p<.0001)$, high vigorousintensity OPA $(\mathrm{r}=0.11, p=.029)$, total OPA [METmin] $(\mathrm{r}=0.16, p=.001)$, total OPA [kcal] $(\mathrm{r}=0.17, p=.0001)$, total PA [METmin] $(\mathrm{r}=0.15, p=.004)$, and total PA [kcal] $(\mathrm{r}=0.14, p=.006)$.
The following relationships were observed between the prevalence of MSD during the last 7 days and PA: the occurrence of elbow pain was correlated with vigorousintensity OPA ( $\mathrm{r}=0.13, p=.015)$, the occurrence of wrist or hand pain was correlated with high vigorous-intensity OPA ( $\mathrm{r}=0.12, p=.017)$, the occurrence of low back pain was correlated with high vigorous-intensity OPA $(\mathrm{r}=$ $0.14, \mathrm{p}=.006$ ), the occurrence of hip or thigh pain was correlated with high vigorous-intensity OPA $(r=0.13$, $\mathrm{p}=.015$ ), and the occurrence of ankle or feet pain was correlated with vigorous-intensity OPA $(\mathrm{r}=0.13, p=$ $.013)$ and high vigorous-intensity OPA $(\mathrm{r}=0.17, p=$ $.001)$. However, these correlations were weak.

The regression model explained only $3 \%$ of the variance of low back pain symptoms. It was a coincidence that with an increase in OPA moderate, the incidence of low back pain symptoms during the last 12 months actually slightly increased. The other parameters included in this model (OPA vigorous, OPA high vigorous, OPA

Table 3 Descriptive statistics of physical activity (PA) among soldiers $(n=373)$

\begin{tabular}{|c|c|c|c|c|}
\hline Weekly PA & Mean \pm SD & Median & Min-Max & $\mathrm{SD}\left(\mathrm{Cl}_{\mathrm{L}}-\mathrm{Cl}_{U}\right)$ \\
\hline OPA Moderate [METmin] & $2404.9 \pm 2595.87$ & 1440 & $0-10,080$ & $2422.0 \pm 2796.8$ \\
\hline OPA Vigorous [METmin] & $1189.5 \pm 1491.22$ & 360 & $0-6480$ & $1391.3 \pm 1606.7$ \\
\hline OPA High vigorous [METmin] & $545.8 \pm 1064.69$ & 0 & $0-6000$ & $993.4 \pm 1147.1$ \\
\hline OPA Total [METmin] & $4140.3 \pm 4155.71$ & 2600 & $0-14,880$ & $3877.4 \pm 4477.5$ \\
\hline OPA Total [kcal] & $5588.1 \pm 5749.32$ & 3499 & $0-22,050$ & $5364.2 \pm 6194.4$ \\
\hline LTPA Moderate [METmin] & $1962.7 \pm 2047.36$ & 1400 & $0-10,080$ & $1910.2 \pm 2205.9$ \\
\hline LTPA Vigorous [METmin] & $1084.7 \pm 1203.76$ & 720 & $0-5040$ & $1123.1 \pm 1297.0$ \\
\hline LTPA High vigorous [METmin] & $702.4 \pm 1099.63$ & 0 & $0-4300$ & $1026.0 \pm 1184.8$ \\
\hline LTPA Total [METmin] & $3749.8 \pm 3458.27$ & 3000 & $0-19,320$ & $3226.6 \pm 3726.0$ \\
\hline LTPA Total [kcal] & $4953.3 \pm 4691.22$ & 3956 & $0-25,760$ & $4377.0 \pm 5054.4$ \\
\hline PA (OPA + LTPA) Total [METmin] & $7890.2 \pm 6463.12$ & 6440 & $0-29,060$ & $6030.2 \pm 6963.5$ \\
\hline PA (OPA + LTPA) Total [kcal] & $6063.3 \pm 5101.43$ & 4964 & $0-24,909$ & $4759.7 \pm 5496.4$ \\
\hline
\end{tabular}

Legend: OPA - occupational physical activity; LTPA - leisure time physical activity; $\mathrm{Cl}$ - confidence interval $(95 \%)$; Total = moderate + vigorous + highly vigorous $P A$ 


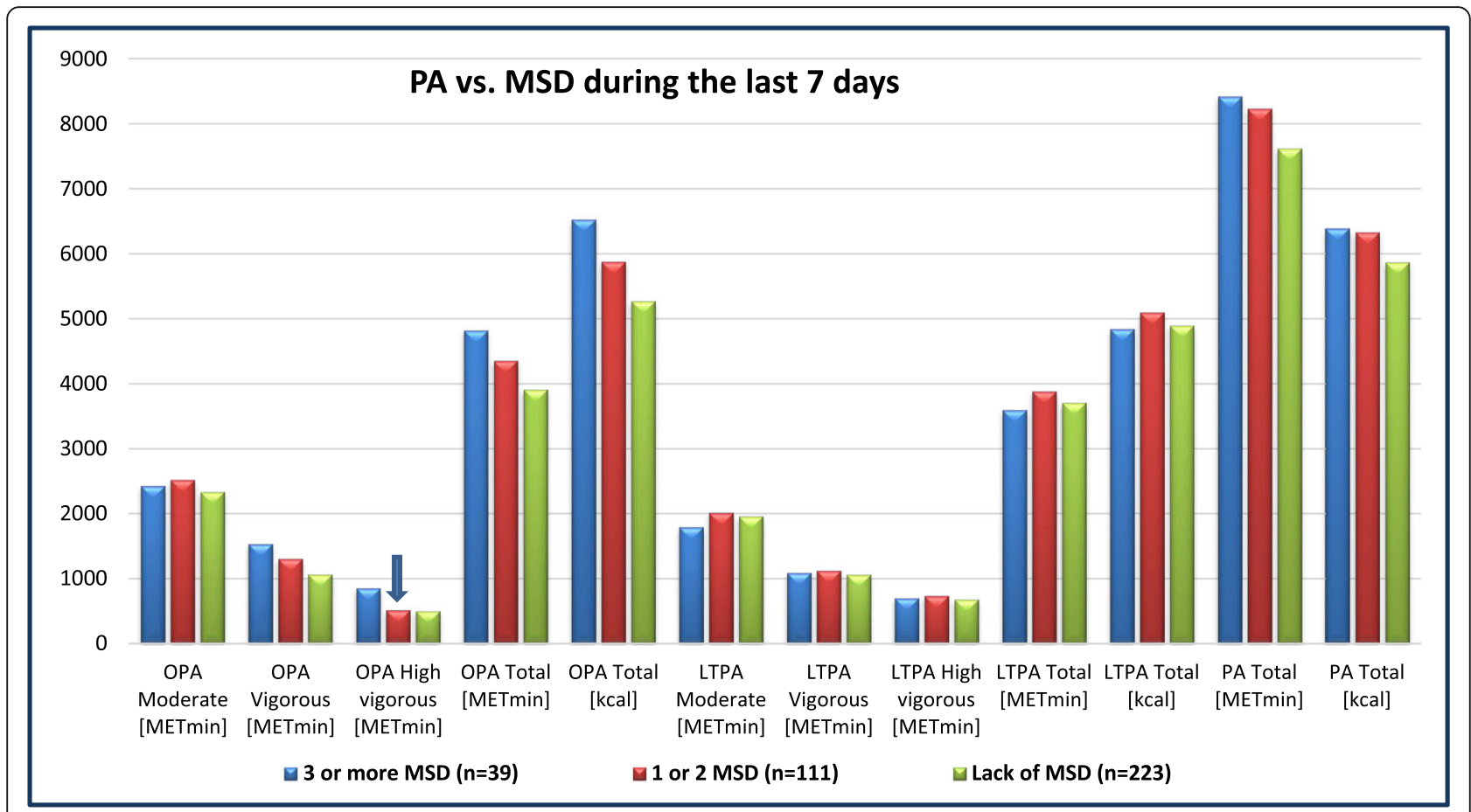

Fig. 1 The level of OPA, LTPA, and total PA vs. the occurrence of MSD during the last 7 days

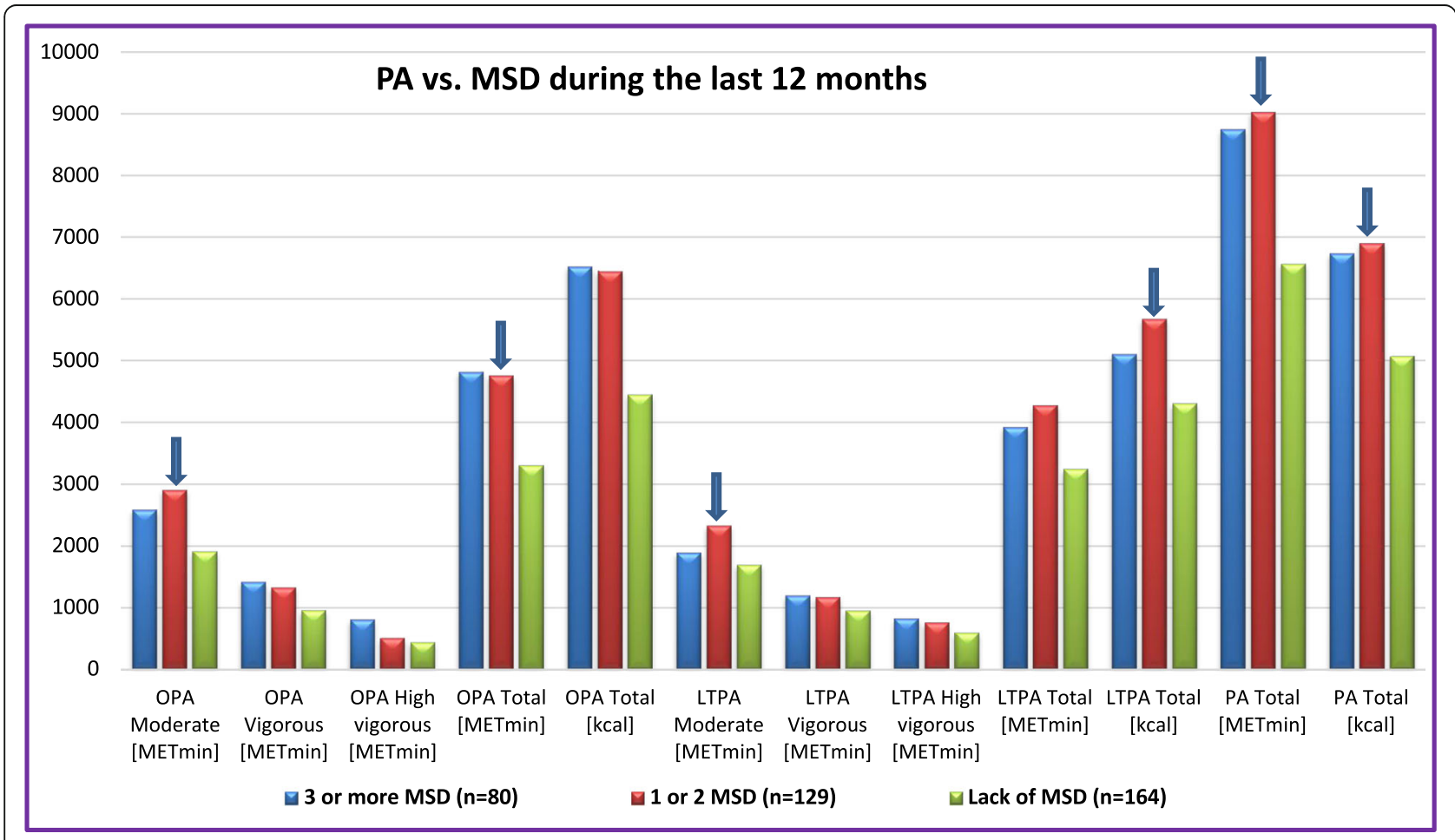

Fig. 2 The level of OPA, LTPA, and total PA vs. the occurrence of MSD during the last 12 months 
total, and gender) were statistically insignificant. Different models were not found.

\section{Discussion}

The aim of this study was to assess the occurrence of self-reported MSD among male and female territorial army soldiers during the COVID-19 pandemic and to investigate whether there was a relationship between OPA, LTPA, and MSD.

An investigation on the 12-month and 7-day prevalence of MSD revealed that the most common was low back pain, followed by neck and knee pain. A total of 56 and $40 \%$ of territorial army soldiers had experienced pain or other discomfort in one or more of nine body regions during the past 12 months and during the past 7 days, respectively. It should be emphasized, however, that these pain symptoms were not related to COVID19 , while myalgia, defined as muscle aches and pain, is a common clinical feature of COVID-19 [28]. Morken et al. in their study of the Royal Norwegian Navy observed that $85 \%$ of these soldiers had experienced MSD, and the most common MSD were also in the lower back, shoulders, and neck. The authors noticed that civilians had a higher prevalence of MSD than military personnel [1]. In Serra et al., police officers often reported pain in the lower back (47\%) and dorsal region (33\%) [29].

We observed relatively high and highly diverse PA among territorial army soldiers. Most of them declared $\mathrm{EE}$ on total PA above $6000 \mathrm{kcal}$ peer week, and the mean and median of the total PA in the studied soldiers was above 6000 METmin per week.

In this cross-sectional study, we investigated the relationship between PA and MSD among soldiers. The study revealed that occupational PA, especially vigorousintensity and high vigorous-intensity OPA, is positively correlated with a higher prevalence of MSD in several regions of the body, i.e. the lower back, elbows, wrists or hands, hips or thighs, and ankles or feet. We observed that along with an increase in energy expenditure on total PA, a greater percentage of respondents experienced low back pain. We also observed that undertaking high vigorous-intensity LTPA is positively correlated with a higher prevalence of wrist or hand pain. Our study indicates that participants who were less physically active experienced MSD less often during the last 12 months. This probably results from the declared high levels of PA among most of the studied soldiers. Our findings are partially in line with previous studies.

As showed in Weyh et al., welders who had a higher physical work load demonstrated a higher prevalence of MSD. The 12-month prevalence of low back pain in welders was $71 \%$, neck pain $61 \%$, and shoulder pain $55 \%$. The authors stated that insufficient LTPA $(<600 \mathrm{MET} /$ week) was associated with low back pain [30].
López-Bueno et al., based on their study including 10,427 active Danish employees, observed an association between LTPA and long-term sickness absence (LTSA). The authors noticed that high LTPA reduced the risk of LTSA by a borderline significant $23 \%$, whereas moderate LTPA also reduced LTSA but a lower percentage than high LTPA [31].

Søgaard et al. revealed that employees with high work activity had a higher frequency of recurring lower back and hand/wrist symptoms, whereas employees with mainly sitting work experienced a higher frequency of recurrent neck symptoms [32]. Our findings were similar; however, we did not find an association between time spent sitting per day and the prevalence of MSD, including neck pain.

The comparison of OPA, LTPA, and MSD between physical education teachers (PET) and other teachers indicated that PET who were more physically active had a significantly lower risk of all MSD during the past year then teachers who were more sedentary [33]. These findings point out that long-term PA is associated with a lower risk of MSD, which is not in line with our study. This is likely due to different levels of PA between teachers and soldiers.

Due to the demands of the annual fitness test, soldiers are obliqued to maintain high fitness levels, which are related to performing physical training. For the same reason, this occupational group might differ from other working groups and should not be compared directly.

The lack of the positive effects of PA, the relationship between vigorous and high-vigorous $\mathrm{PA}$, and the occurrence of MSD in the hips or thighs or ankles or feet observed in our study is supported by studies that indicate physical training as the cause of injuries in the lower limbs [34, 35].

The opposite findings were obtained by Serra et al. who indicated that undergoing physical activities during the last 12 months reduced the odds of getting MSD by $30 \%$. Police officers who had performed PA during the last 12 months reported less occupational stress than those who did not. However, the authors mainly focused on the assessment of stress perception, whereas information about PA was limited to one question regarding performing some type of physical exercise more than three times a week [29].

Our results, based on the cross-sectional study design, do not allow us to point out a clear causal relationship between PA and MSD. However, we may assume that performing high-intensity PA, the majority as OPA, causes the more frequent occurrence of MSD.

\section{Strengths and limitations of the study}

The study was conducted during the COVID-19 pandemic among a specific group of workers with relatively 
high PA. These results should neither be generalized to other working populations nor to non-pandemic periods.

There are several limitations to this study which are worth mentioning. In this study, PA was measured by a questionnaire, a subjective method of assessing PA, and the validity and reliability of this method may be questionable [36]. As has been shown in previous studies, self-reported PA is often overestimated [37, 38]. However, a questionnaire may be the one practical method of evaluating PA among a large population. Another limitation is not distinguishing between domestic PA and active travel as domains of PA due to the sparse reporting of these activities, whereas participants reported occupational and leisure time PA separately. Further, another limitation is the lack of information about education, social status, and physical fitness. However, as was shown in the inclusion criteria, a fairly homogeneous group was examined. We assumed that the physical fitness of the studied soldiers would be similar due to the requirement to pass obligatory annual fitness tests. On the other hand, this study also included the following potential confounders: age, gender, education.

\section{Conclusions}

The most common MSD among Polish territorial army soldiers were low back pain, followed by neck and knee pain. Participants had relatively high and highly diverse levels of PA.

The study revealed that the OPA of the studied soldiers, especially vigorous-intensity and high vigorousintensity OPA, was positively correlated with a prevalence of MSD in several regions of the body, i.e. the lower back, elbows, wrists or hands, hips or thighs, ankles or feet. Along with the increase in energy expenditure on total PA, a greater percentage of respondents experienced low back pain.

Vigorous and high vigorous-intensity PA may contribute to the occurrence of MSD.

\section{Abbreviations \\ PA: physical activity; MSD: musculoskeletal disorders; OPA: occupational physical activity; LTPA: leisure time physical activity; SDPAR: Seven-Day Physical Activity Recall; NMQ: Nordic Musculoskeletal Questionnaire; EE: energy expenditure; BMI: body mass index}

\section{Acknowledgments}

The authors would like to thank Colonel Tomasz Białas and Second Lieutenant Dr. Kamila Borowiec for enabling the survey to be conducted among the soldiers of the 13th Silesian Territorial Defense Brigade. The authors also thank the soldiers of the 13th Silesian Territorial Defense Brigade for their participation in the study.

\section{Authors' contributions}

M.G. and E.S-K. conceived and designed the study; E.S-K. performed the study: M.G. analyzed the data and wrote the paper. All authors read and approved the final manuscript.

\section{Funding}

The study received statutory funding from the Jerzy Kukuczka Academy of Physical Education, Katowice, Poland; no additional funding was received.

\section{Availability of data and materials}

Data and publication materials are available upon request from M.G. (m. grabara@awf.katowice.pl).

\section{Declarations}

\section{Ethics approval and consent to participate}

The subjects were informed of the study goals and test protocols before giving their signed informed consent for participation. The study protocol received approval from the Local Bioethics Committee (certificate of approval No. KB/02/12) of the Jerzy Kukuczka Academy of Physical Education in Katowice (Poland) according to the principles and policies of the Declaration of Helsinki.

\section{Consent for publication}

Not applicable.

\section{Competing interests}

The authors declare no conflict of interest.

Received: 6 June 2021 Accepted: 25 August 2021

Published online: 16 September 2021

\section{References}

1. Morken T, Magerøy N, Moen BE. Physical activity is associated with a low prevalence of musculoskeletal disorders in the Royal Norwegian Navy: a cross sectional study. BMC Musculoskelet Disord. 2007;8(1):56. https://doi. org/10.1186/1471-2474-8-56

2. Buyukavci R, Akturk S, Akturk U. The relationship between musculoskeletal disorders and physical activity among nursing students. Med Sci Int Med J. 2020;9(2):462. https://doi.org/10.5455/medscience.2020.09.9252.

3. Wongwitwichote $\mathrm{K}$, Jalayondeja W, Mekhora K, Jalayondeja C. Physical activity, sitting time and work-related musculoskeletal disorders in computer workers. Japanese J Ergon. 2017;53:S450-3.

4. Puig-Ribera A, Martínez-Lemos I, Giné-Garriga M, González-Suárez ÁM, BortRoig J, Fortuño J, et al. Self-reported sitting time and physical activity: interactive associations with mental well-being and productivity in office employees. BMC Public Health. 2015;15:1-10.

5. Halvarsson A, Seth M, Tegern M, Broman L, Larsson H. Remarkable increase of musculoskeletal disorders among soldiers preparing for international missions-comparison between 2002 and 2012. BMC Musculoskelet Disord. 2019;20:1-7.

6. Tegern M, Aasa U, Äng BO, Larsson H. Musculoskeletal disorders and their associations with health-and work-related factors: a cross-sectional comparison between Swedish air force personnel and army soldiers. BMC Musculoskelet Disord. 2020;21:1-14.

7. Zambraski EJ, Yancosek KE. Prevention and rehabilitation of musculoskeletal injuries during military operations and training. J Strength Cond Res. 2012; 26(Supplement 2):S101-6. https://doi.org/10.1519/JSC.0b013e31822e7721.

8. Monnier A, Djupsjöbacka M, Larsson H, Norman K, Äng BO. Risk factors for back pain in marines; a prospective cohort study. BMC Musculoskelet Disord. 2016;17:1-12.

9. Li J, Loerbroks A, Angerer P. Physical activity and risk of cardiovascular disease: what does the new epidemiological evidence show? Curr Opin Cardiol. 2013;28(5):575-83. https://doi.org/10.1097/HCO.0b013e328364289c.

10. Holtermann A, Hansen JV, Burr H, Søgaard K, Sjøgaard G. The health paradox of occupational and leisure-time physical activity. Br J Sports Med. 2012;46(4):291-5. https://doi.org/10.1136/bjsm.2010.079582.

11. Hallman DM, Jørgensen MB, Holtermann A. On the health paradox of occupational and leisure-time physical activity using objective measurements: effects on autonomic imbalance. PLoS One. 2017;12:1-16.

12. Y.A. Kesaniemi, J. Danforth E., M.D. Jensen, P.G. Kopelman, P. Lefebvre and B. A. Reeder, Dose-response issues concerning physical activity and health: An evidence-based symposium, Med. Sci. Sports Exerc. 33 (2001), pp. 351-358.

13. WHO WHO. Guidelines on physical activity and sedentary: Behaviour; 2020.

14. Nawrocka A, Mynarski W, Powerska A, Grabara M, Groffik D, Borek Z. Healthoriented physical activity in prevention of musculoskeletal disorders among 
young polish musicians. Int J Occup Med Environ Health. 2014;27(1):28-37. https://doi.org/10.2478/s13382-014-0224-5.

15. S. Murata, T. Doi, R. Sawa, R. Nakamura, T. Isa, A. Ebina et al., Association between objectively measured physical activity and the number of chronic musculoskeletal pain sites in community-dwelling older adults, Pain Med. (United States) 20 (2019), .

16. Nawrocka A, Niestrój-Jaworska M, Mynarski A, Polechoński J. Association between objectively measured physical activity and musculoskeletal disorders, and perceived work ability among adult, middle-aged and older women. Clin Interv Aging. 2019;14:1975-83. https://doi.org/10.2147/CIA.S2 04196.

17. Hildebrandt VH, Bongers PM, Dul J, Van Dijk FJH, Kemper HCG. The relationship between leisure time, physical activities and musculoskeletal symptoms and disability in worker populations. Int Arch Occup Environ Health. 2000;73(8):507-18. https://doi.org/10.1007/s004200000167.

18. Hoogendoorn WE, Van Poppel MNM, Bongers PM, Koes BW, Bouter LM. Physical load during work and leisure time as risk factors for back pain. Scand J Work Environ Health. 1999;25(5):387-403. https://doi.org/10.5271/ sjweh.451.

19. Alvarez-Risco A, Mejia CR, Delgado-Zegarra J, Del-Aguila-Arcentales S, ArceEsquivel AA, Valladares-Garrido MJ, et al. The Peru approach against the COVID-19 infodemic: insights and strategies. Am J Trop Med Hyg. 2020; 103(2):583-6. https://doi.org/10.4269/ajtmh.20-0536.

20. S.X. Zhang, S. Sun, A. Afshar Jahanshahi, A. Alvarez-Risco, V.G. Ibarra, J. Li et al., Developing and testing a measure of COVID-19 organizational support of healthcare workers - results from Peru, Ecuador, and Bolivia, Psychiatry Res. 291 (2020),

21. Chen X, Zhang SX, Jahanshahi AA, Alvarez-Risco A, Dai H, Li J, et al. Belief in a COVID-19 conspiracy theory as a predictor of mental health and wellbeing of health care workers in Ecuador: cross-sectional survey study. JMIR Public Heal Surveill. 2020;6:1-7.

22. Situation by Region, Country, Territory \& Area.

23. Kuorinka I, Jonsson B, Kilbom A, Vinterberg H, Biering-Sørensen F, Andersson G, et al. Standardised Nordic questionnaires for the analysis of musculoskeletal symptoms. Appl Ergon. 1987;18(3):233-7. https://doi.org/1 0.1016/0003-6870(87)90010-X.

24. Nawrocka A, Mynarski W, Powerska-Didkowska A, Grabara M, Garbaciak W. Musculoskeletal pain among polish music school students. Med Probl Perform Art. 2014;29(2):64-9. https://doi.org/10.21091/mppa.2014.2015.

25. Mynarski W, Grabara M, Nawrocka A, Niestrój-Jaworska M, Wołkowycka B, Cholewa J. Physical recreational activity and musculoskeletal disorders in nurses. Med Pr. 2014;65(2):181-8.

26. Gross LD, Sallis JF, Buono MJ, Roby JJ, Nelson JA. Reliability of interviewers using the seven-day physical activity recall. Res Q Exerc Sport. 1990;61(4): 321-5. https://doi.org/10.1080/02701367.1990.10607494.

27. Kaleta $D$, Jegier $A$. Occupational energy expenditure and leisure-time physical activity. Int J Occup Med Environ Health. 2005;18(4):351-6.

28. S.L. Ramani, J. Samet, C.K. Franz, C. Hsieh, C. V. Nguyen, C. Horbinski et al., Musculoskeletal involvement of COVID-19: review of imaging, Skeletal Radiol. (2021), pp. 1763-1773.

29. Serra MVGB, Scalon JD, Tonello MGM, Quemelo PRV. Musculoskeletal disorders, stress perception and physical activity in police officers. Fisioter e Pesqui. 2020;27(1):22-7. https://doi.org/10.1590/1809-2950/18029227012020.

30. C. Weyh, C. Pilat and K. Krüger, Musculoskeletal disorders and level of physical activity in welders, Occup. Med. (Chic. III). 70 (2020),

31. López-Bueno R, Sundstrup E, Vinstrup J, Casajús JA, Andersen LL. High leisure-time physical activity reduces the risk of long-term sickness absence. Scand J Med Sci Sport. 2020;30(5):939-46. https://doi.org/10.1111/sms.13629.

32. Søgaard K, Juul-Kristensen B, Sjøgaard G, Hannetz H, Burr H. Prevalence and prediction of recurrent musculoskeletal symptoms during a ten-year period and the significance of physical activity at work. Osteoarthr Cartil. 2009:17: S192. https://doi.org/10.1016/S1063-4584(09)60384-8.

33. Pihl E, Matsin T, Jürimäe T. Physical activity, musculoskeletal disorders and cardiovascular risk factors in male physical education teachers. J Sports Med Phys Fitness. 2002;42(4):466-71

34. Almeida SA, Williams KM, Shaffer RA, Brodine SK. Epidemiological patterns of musculoskeletal injuries and physical training. Med Sci Sports Exerc. 1999; 31(8):1176-82. https://doi.org/10.1097/00005768-199908000-00015.

35. Heir T. Musculoskeletal injuries in officer training: one-year follow-up. Mil Med. 1998:163(4):229-32. https://doi.org/10.1093/milmed/163.4.229.
36. Shephard R. Limits to the measurement of habitual physical activity by questionnaires. Br J Sports Med. 2003;37(>3):197-206. https://doi.org/10.113 6/bjsm.37.3.197.

37. Hagstromer M, Ainsworth BE, Oja P, Sjostrom M. Comparison of a subjective and an objective measure of physical activity in a population sample. J Phys Act Health. 2010;7(4):541-50. https://doi.org/10.1123/jpah.7.4.541.

38. Wick K, Faude O, Schwager S, Zahner L, Donath L. Deviation between selfreported and measured occupational physical activity levels in office employees: effects of age and body composition. Int Arch Occup Environ Health. 2016;89(4):575-82. https://doi.org/10.1007/s00420-015-1095-1.

\section{Publisher's Note}

Springer Nature remains neutral with regard to jurisdictional claims in published maps and institutional affiliations.
Ready to submit your research? Choose BMC and benefit from:

- fast, convenient online submission

- thorough peer review by experienced researchers in your field

- rapid publication on acceptance

- support for research data, including large and complex data types

- gold Open Access which fosters wider collaboration and increased citations

- maximum visibility for your research: over $100 \mathrm{M}$ website views per year

At BMC, research is always in progress.

Learn more biomedcentral.com/submissions 